Supplementary Information

\title{
Effects of Site and Magnetic Disorder on the Oxygen Vacancy Formation, Electronic and Optical Properties of $\mathrm{La}_{\mathrm{x}} \mathrm{Sr}_{1-\mathrm{x}} \mathrm{CoO}_{3-\delta}$ and $\mathrm{SrFe}_{\mathrm{y}} \mathrm{Co}_{1-\mathrm{y}} \mathrm{O}_{3-\delta}$
}

\author{
Ting Jia, Jonathan W. Lekse, Gregory A. Hackett and Yuhua Duan* \\ National Energy Technology Laboratory, United States Department of Energy, Pittsburgh, \\ Pennsylvania 15236, USA
}

\section{Table of Contents}

Figure S1: The optimized crystal structures in the site ordered FM phases.

Figure S2: The optimized crystal structures in the site disordered FM phases.

Figure S3. The optimized crystal structures in the site disordered PM phases.

Figure S4: The optimized crystal structures with one oxygen vacncy in the site ordered FM

phases.

Figure S5: The optimized crystal structures with one oxygen vacncy in the site disordered FM

phases.

Figure S6: The optimized crystal structures with one oxygen vacncy in the site disordered PM

phases.

Figure S7: The partial DOS in the site ordered FM phase.

Figure S8: The absorption coefficient in the site ordered FM phase. 

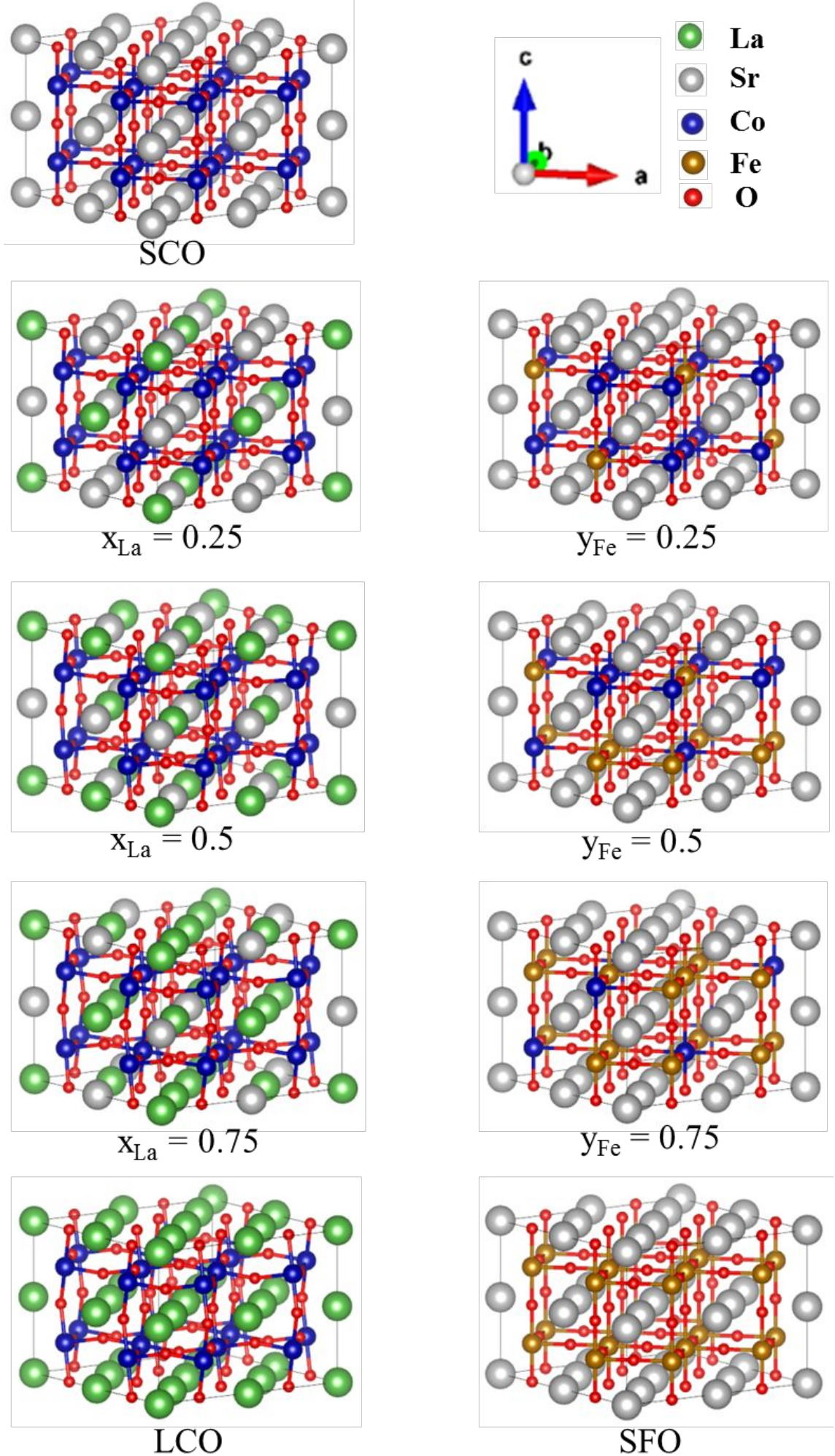

Figure S1: The optimized crystal structures of $\mathrm{La}_{\mathrm{x}} \mathrm{Sr}_{1-\mathrm{x}} \mathrm{CoO}_{3}$ and $\mathrm{SrFe}_{\mathrm{y}} \mathrm{Co}_{1-\mathrm{y}} \mathrm{O}_{3} \cdot(\mathrm{x} / \mathrm{y}=0,0.25,0.5$, $0.75,1)$ in the site ordered FM phases. 

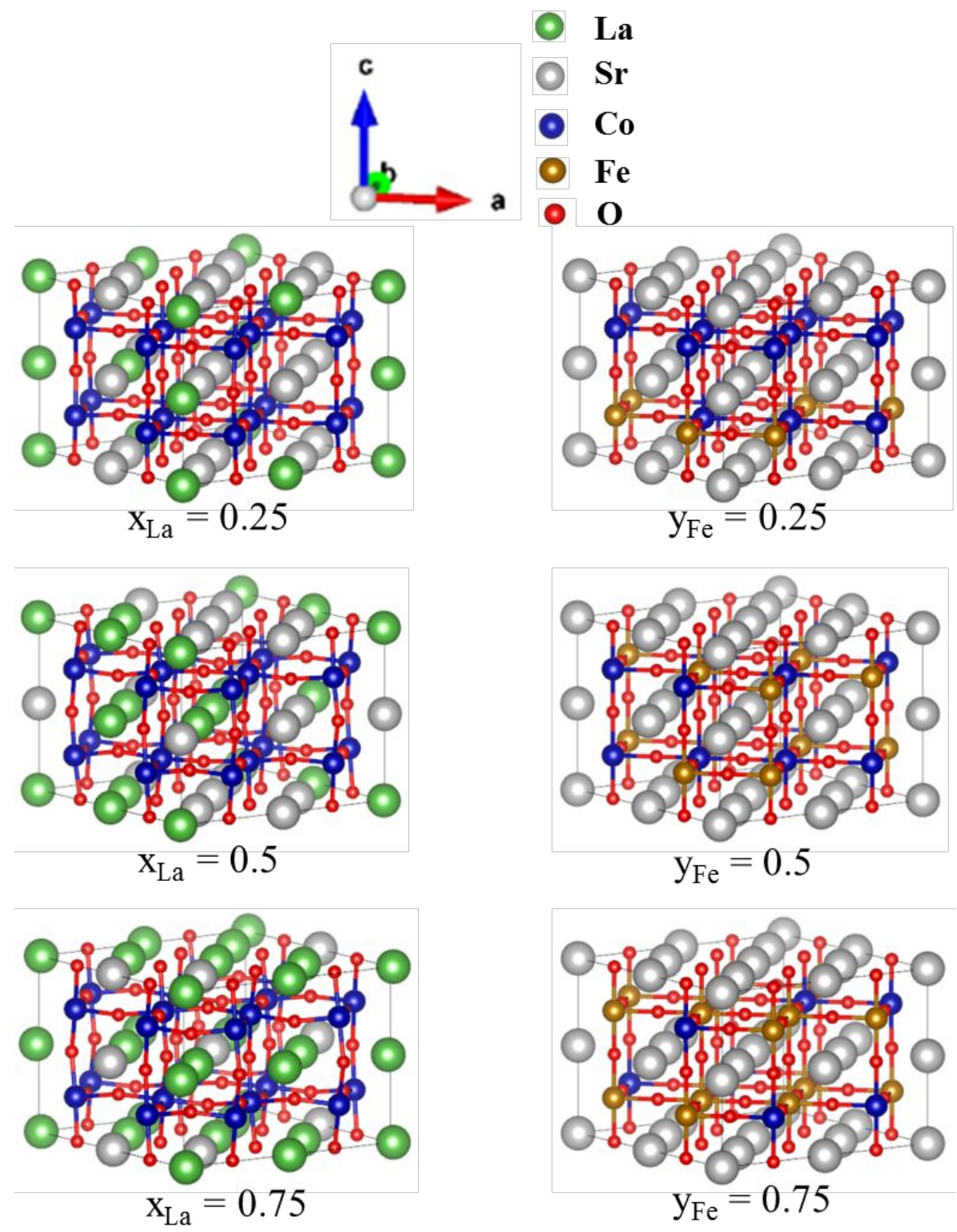

Figure S2: The optimized crystal structures of $\mathrm{La}_{\mathrm{x}} \mathrm{Sr}_{1-\mathrm{x}} \mathrm{CoO}_{3}$ and $\mathrm{SrFe}_{\mathrm{y}} \mathrm{Co}_{1-\mathrm{y}} \mathrm{O}_{3} \cdot(\mathrm{x} / \mathrm{y}=0.25,0.5$, 0.75 ) in the site disordered FM phases. 

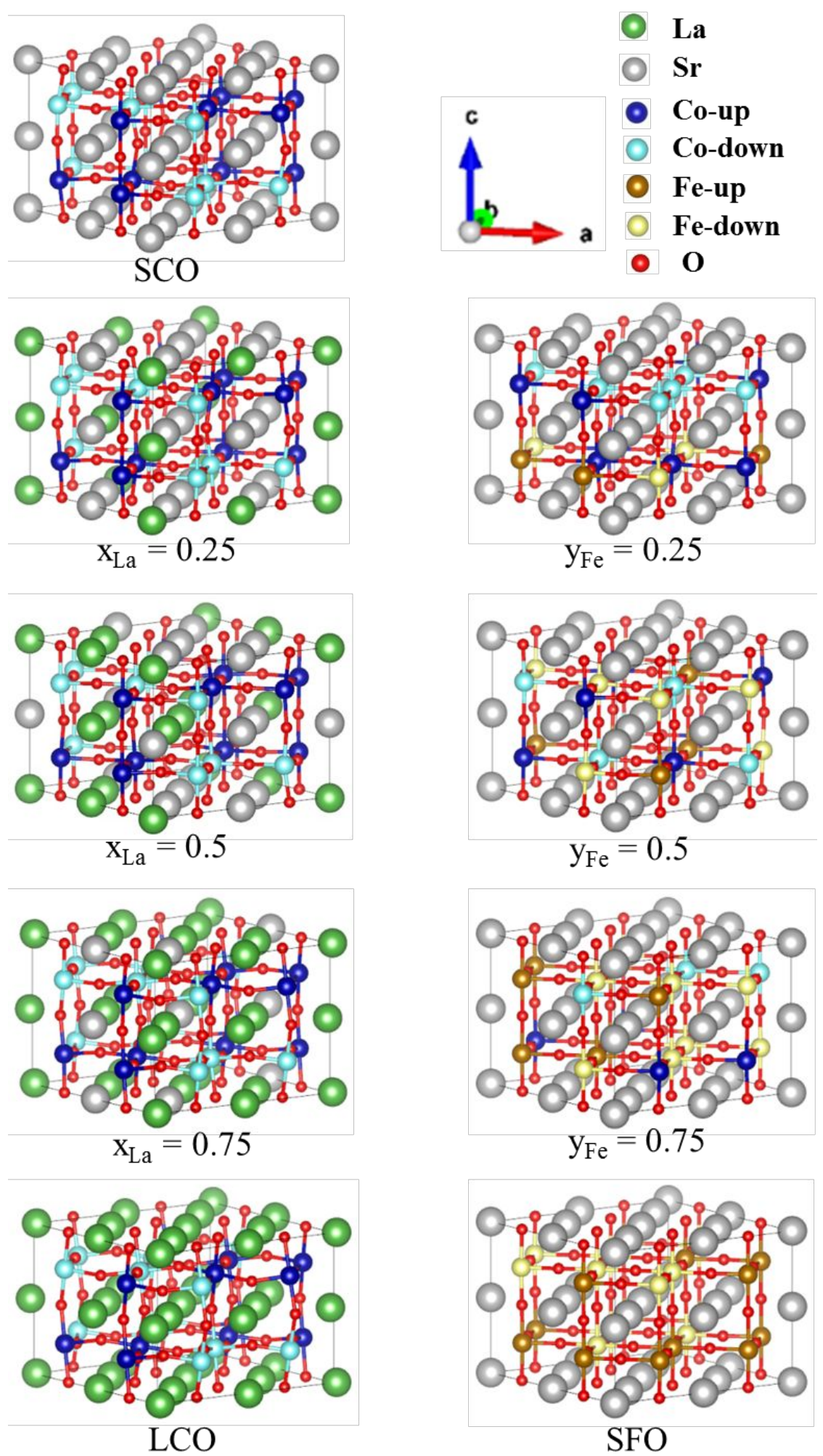

Figure S3: The optimized crystal structures of $\mathrm{La}_{\mathrm{x}} \mathrm{Sr}_{1-\mathrm{x}} \mathrm{CoO}_{3}$ and $\mathrm{SrFe}_{\mathrm{y}} \mathrm{Co}_{1-\mathrm{y}} \mathrm{O}_{3} \cdot(\mathrm{x} / \mathrm{y}=0,0.25,0.5$, $0.75,1)$ in the site disordered PM phases. 

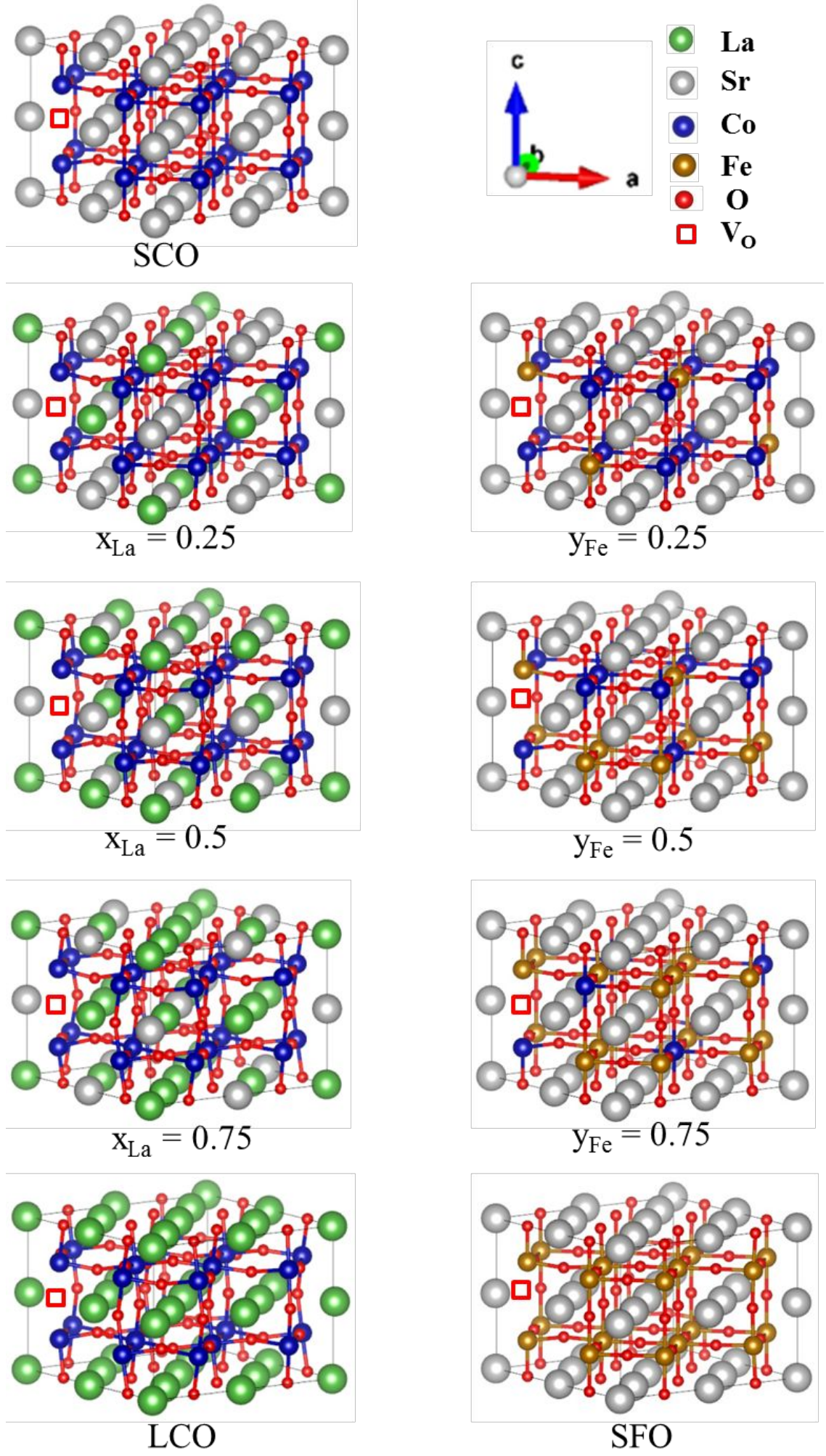

Figure S4: The optimized crystal structures of $\mathrm{La}_{\mathrm{x}} \mathrm{Sr}_{1-\mathrm{x}} \mathrm{CoO}_{3}$ and $\mathrm{SrFe}_{\mathrm{y}} \mathrm{Co}_{1-\mathrm{y}} \mathrm{O}_{3} \cdot(\mathrm{x} / \mathrm{y}=0,0.25,0.5$, $0.75,1)$ with one oxygen vacncy in the site ordered FM phases. 


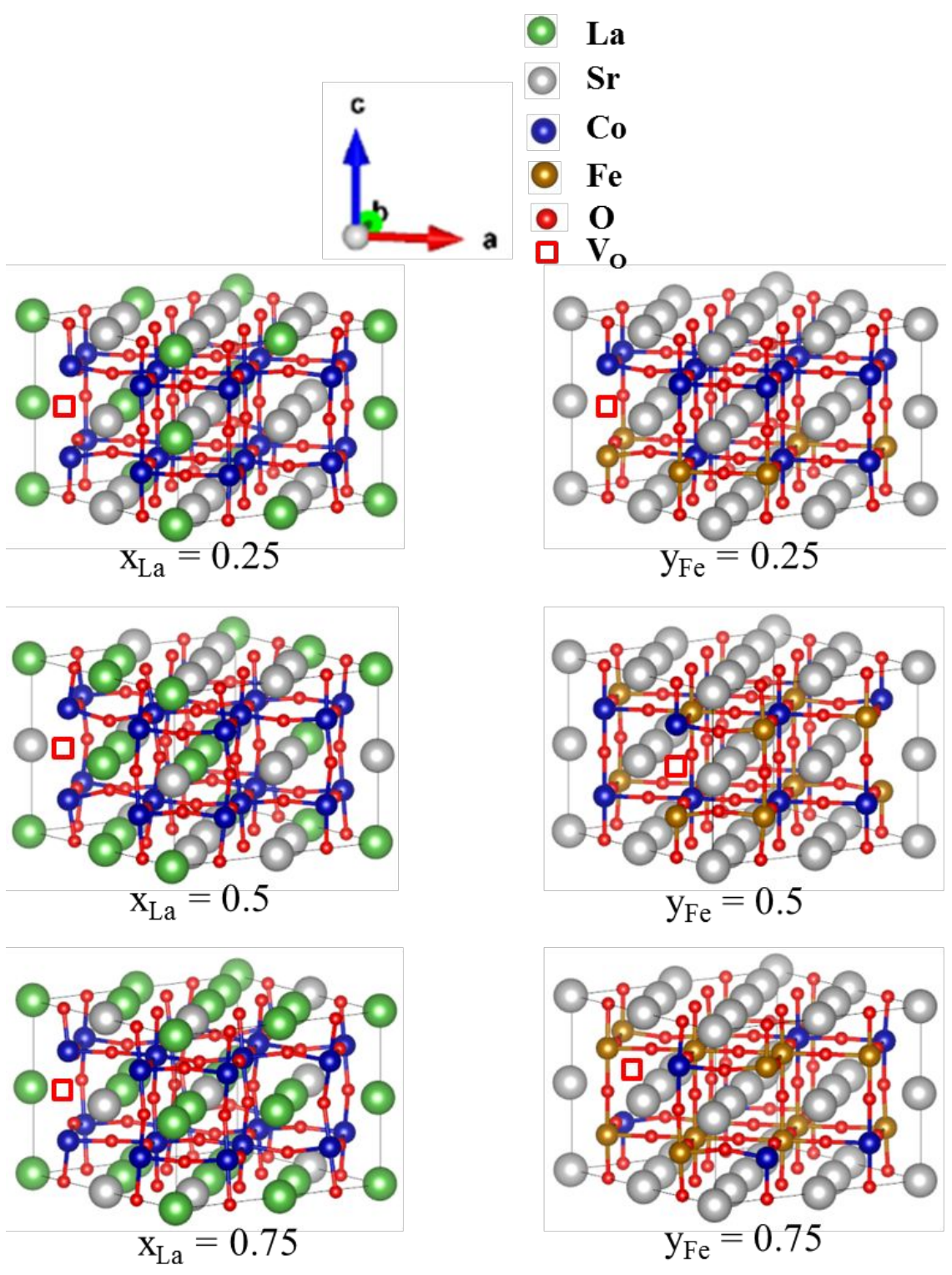

Figure S5: The optimized crystal structures of $\mathrm{La}_{\mathrm{x}} \mathrm{Sr}_{1-\mathrm{x}} \mathrm{CoO}_{3}$ and $\mathrm{SrFe}_{\mathrm{y}} \mathrm{Co}_{1-\mathrm{y}} \mathrm{O}_{3} \cdot(\mathrm{x} / \mathrm{y}=0.25,0.5$, 0.75 ) with one oxygen vacancy in the site disordered FM phases. 

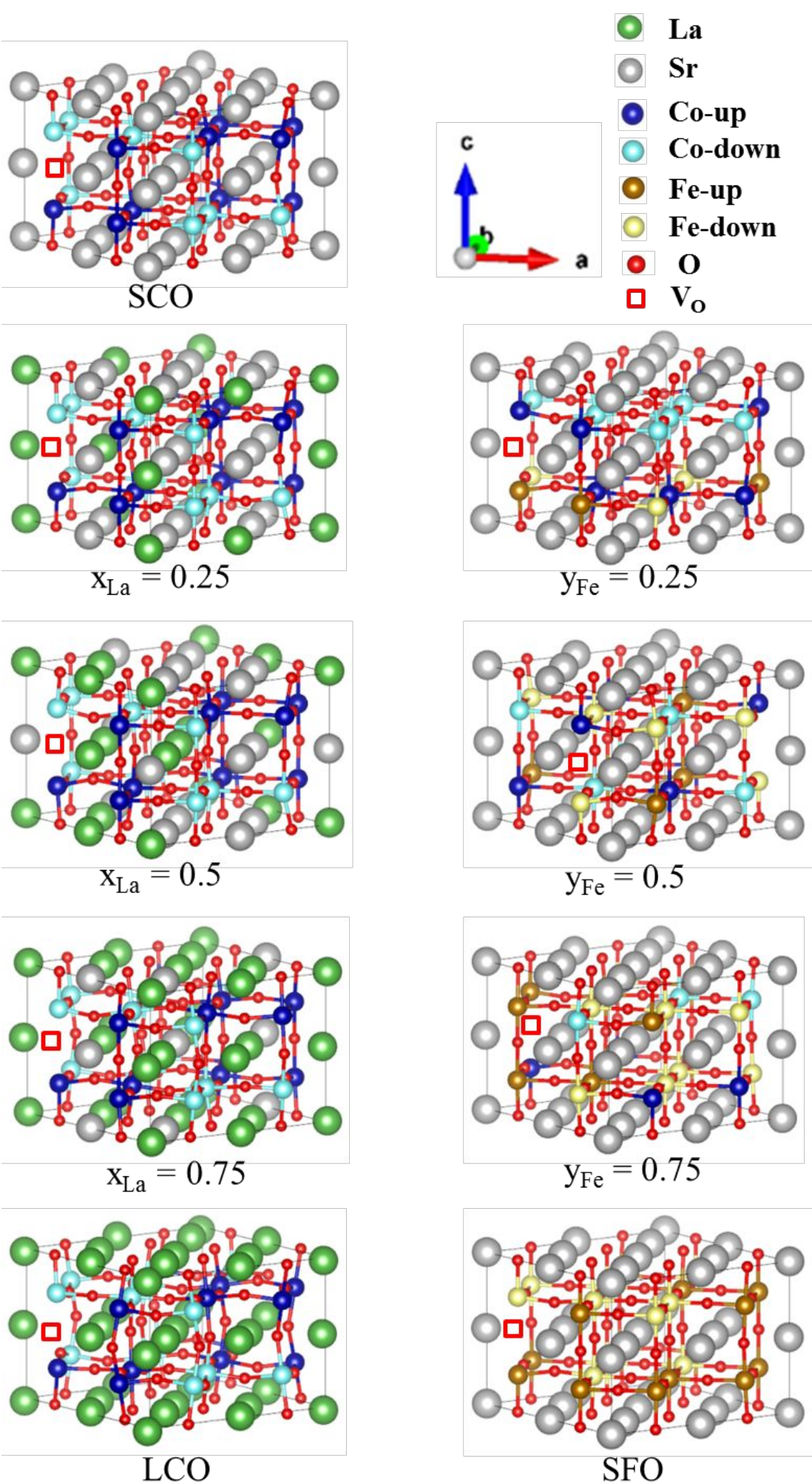

Figure S6: The optimized crystal structures of $\mathrm{La}_{\mathrm{x}} \mathrm{Sr}_{1-\mathrm{x}} \mathrm{CoO}_{3}$ and $\mathrm{SrFe}_{\mathrm{y}} \mathrm{Co}_{1-\mathrm{y}} \mathrm{O}_{3} \cdot(\mathrm{x} / \mathrm{y}=0,0.25,0.5$, $0.75,1)$ with one oxygen vacancy in the site disordered PM phases. 


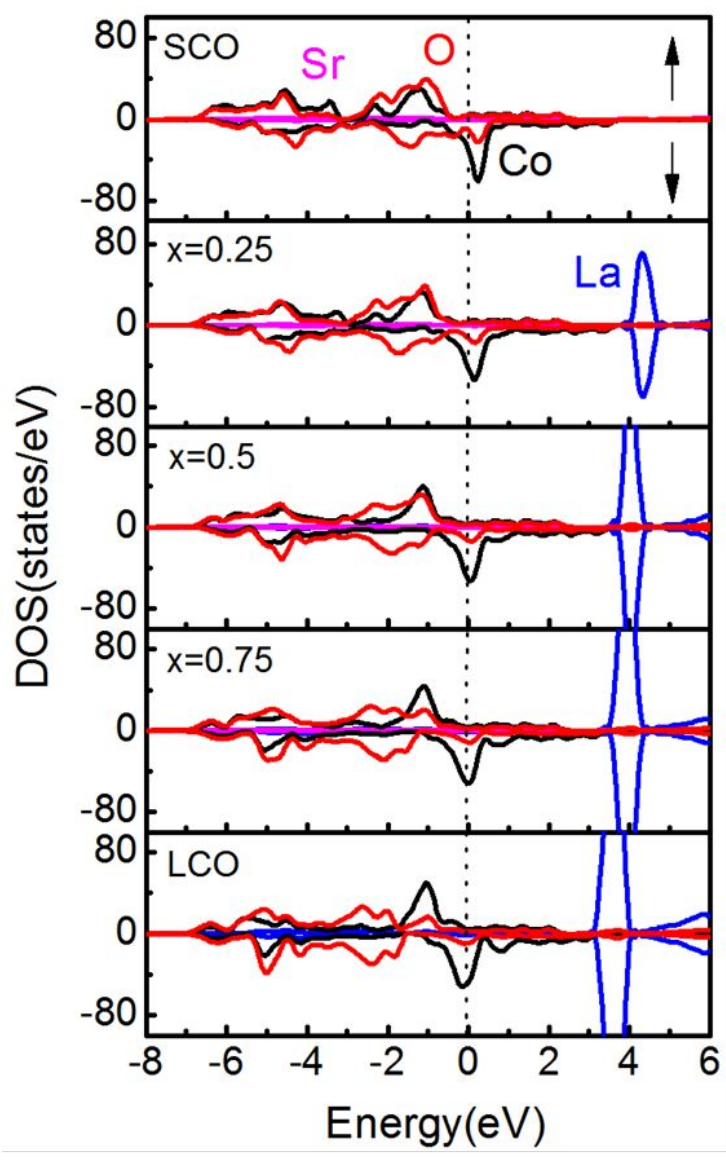

(a)

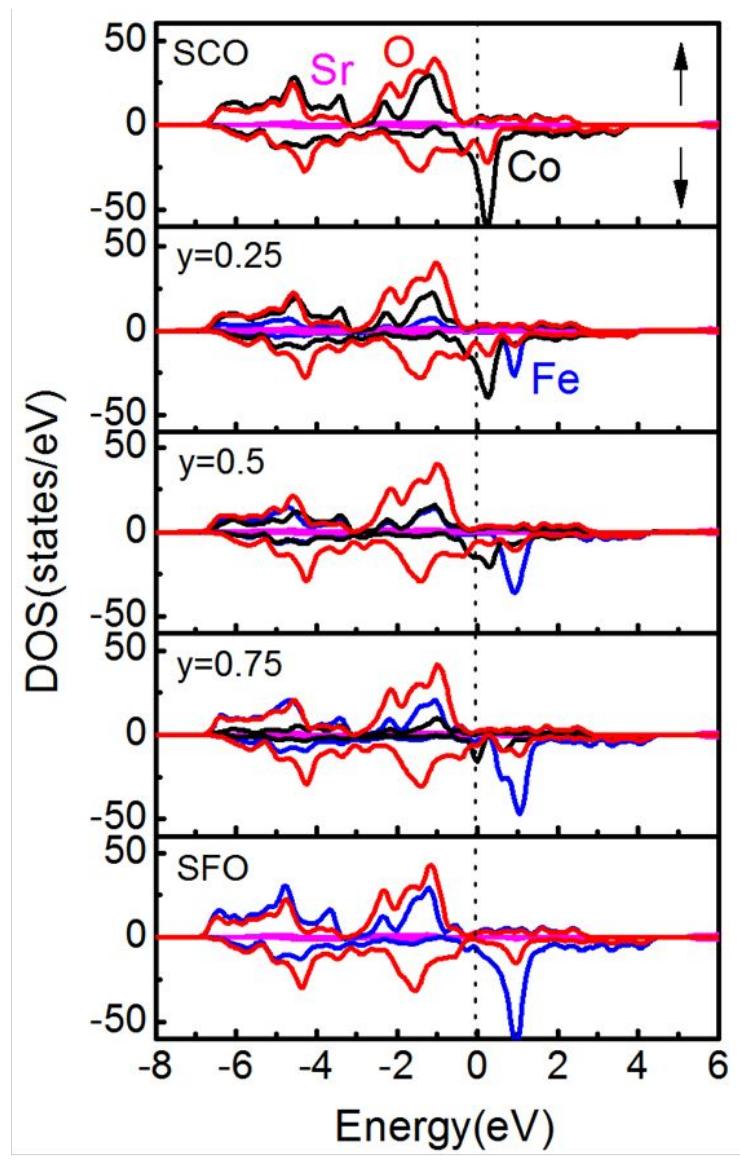

(b)

Figure S7: The partial DOS for (a) $\mathrm{La}_{\mathrm{x}} \mathrm{Sr}_{1-\mathrm{x}} \mathrm{CoO}_{3}(\mathrm{x}=0,0.25,0.5,0.75,1)$ and (b) $\mathrm{SrFe}_{\mathrm{y}} \mathrm{Co}_{1-\mathrm{y}} \mathrm{O}_{3}$ $(\mathrm{y}=0,0.25,0.5,0.75,1)$ in the site ordered FM phase. The Fermi level (dotted line) is set at 0 $\mathrm{eV}$. 

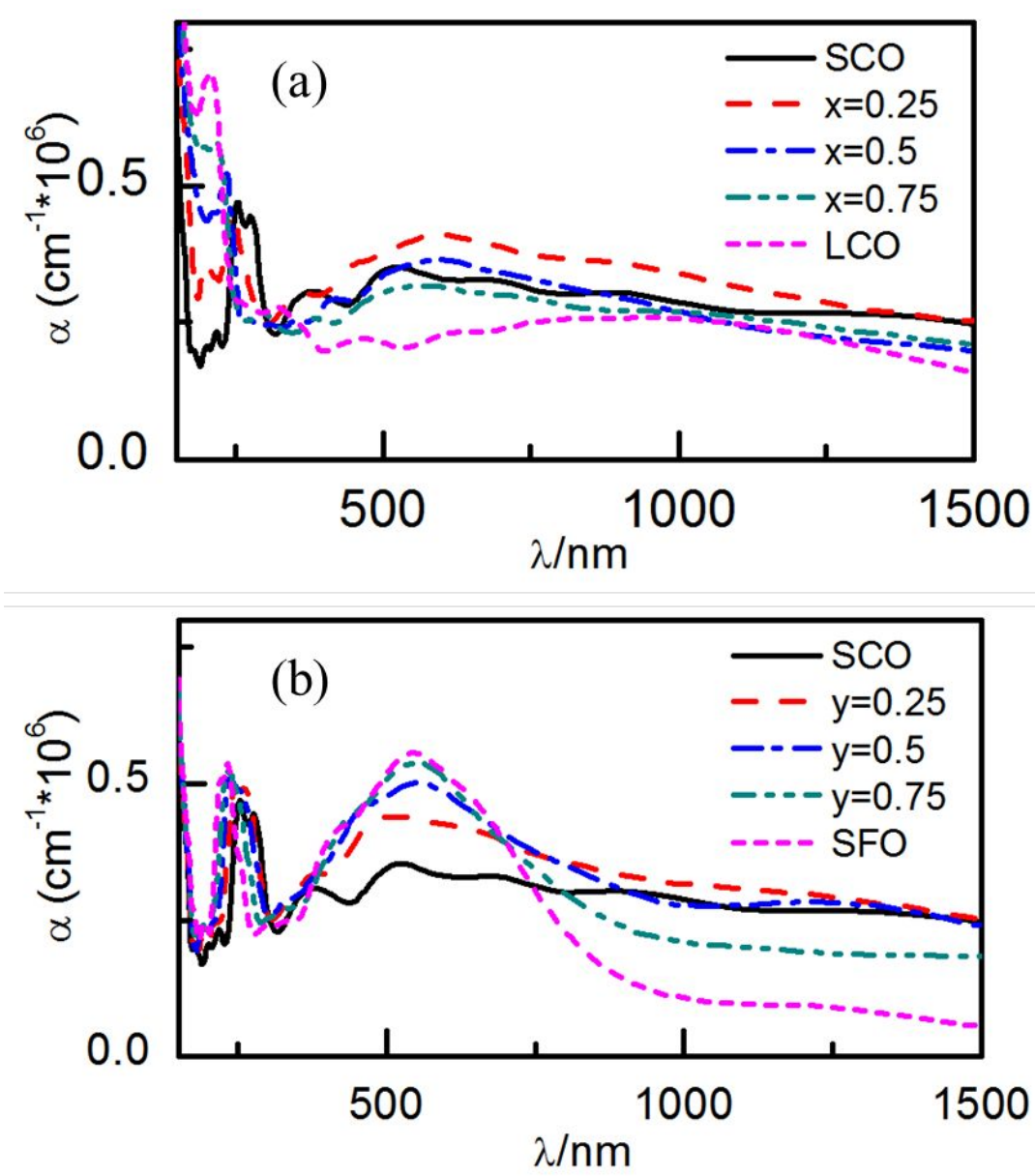

Figure S8: The absorption coefficient ( $\alpha$ ) of (a) $\mathrm{La}_{\mathrm{x}} \mathrm{Sr}_{1-\mathrm{x}} \mathrm{CoO}_{3}(\mathrm{x}=0,0.25,0.5,0.75,1)$ and (b) $\mathrm{SrFe}_{\mathrm{y}} \mathrm{Co}_{1-\mathrm{y}} \mathrm{O}_{3}(\mathrm{y}=0,0.25,0.5,0.75,1)$ in the site ordered FM phase as a function of wavelength $(\lambda)$. 